\title{
Sobre a possibilidade de uma filosofia da técnica correta e verdadeira
}

Gerson Brea

Universidade de Brasília

\section{Resumo}

Esse artigo pretende aproximar-se do fenômeno da técnica, a partir de uma discussão do texto A questão da técnica, de Martin Heidegger. Após uma breve introdução que apresenta diversos momentos de concepções antropológicas da técnica, a discussão analisará passagens centrais da proposta heideggeriana em que a essência da técnica é compreendida como um acontecimento da verdade. Finalmente, o artigo tecerá algumas reflexões, inspiradas em um trabalho de Alfred Nordmann, sobre os limites que o pensamento de Heidegger nos impõe quando pretendemos pensar outras possibilidades de uma filosofia da técnica.

Palavras-chave: Heidegger; técnica; verdade.

\begin{abstract}
This article approaches the question of technic through an analysis of Martin Heidegger's work The question concerning technology. After a brief introduction in which several anthropological conceptions regarding technic are presented, the article discusses key elements of the heideggerian proposal about the essence of technic as an event of truth. It concludes by reflecting on Alfred Nordmann's work on the limits which Heidegger's thought imposes us when we think about alternative possibilities for a philosophy of technic.
\end{abstract}

Keywords: Heidegger; technic; truth. 
técnica determina nossas vidas. Isso parece um fato incontestável. E que ocorre não somente naqueles momentos em 1 que utilizamos um eletrodoméstico, trabalhamos em nosso computador ou nos deslocamos para outro continente. Mesmo sem sabermos direito como defini-la a técnica parece estar aí presente, ameaçando constantemente adentrar e determinar todas as nossas atividades. O mais curioso é que nem sequer a percebemos! Andreas Luckner, recorrendo a Don Ihde, aponta para uma "textura tecnológica" caracterizada justamente pelo fato de não ser percebida. É justamente isso que chama mais a atenção: o fato da técnica não chamar atenção, "pelo menos enquanto ela funciona" (Luckner, 2008, p. 9).

Mas será mesmo assim? Estariam hoje todos os âmbitos de nossas atividades determinados pela técnica? Seria a técnica e seu domínio um fenômeno novo? Ou estaríamos aqui diante de algo tão antigo como a humanidade? Fato é que nossa época é frequentemente denominada de "era tecnológica" ou "era da técnica". Por quê? Seria essa realmente uma caracterização precisa somente para nosso tempo?

Certamente, perguntas como essas questões brotam de uma précompreensão do que significa "técnica" e, ao mesmo tempo, da vagueza desse conceito. Refletir sobre a técnica, sobre suas influências e consequências, sem possuirmos uma ideia concreta do que realmente ela é, se torna um dos maiores desafios de uma filosofia da técnica. Como pensar uma filosofia da técnica, se agora, além das intermináveis querelas advindas das dificuldades de se definir a filosofia, nos deparamos com a grande volatilidade do conceito de técnica?

Primeiramente, não é difícil perceber que muitas das discussões filosóficas sobre a técnica se dão frequentemente no campo da filosofia prática. Como devemos lidar com os avanços da técnica? Como a técnica pode nos ser útil, propiciar bem-estar e até felicidade? Quais as consequências da tecnicização do mundo para a visão que temos do 
homem? A condição humana, de Hannah Arendt, $O$ princípio da responsabilidade, de Hans Jonas, Die Antiquiertheit des Menschen, de Günther Anders, são apenas alguns exemplos conhecidos de pensadores todos eles oportunamente ex-alunos de Heidegger - que se ocuparam intensivamente com questões semelhante a essas. Contudo, a tendência em analisar a técnica, preocupando-se fundamentalmente com suas implicações éticas e políticas, ou seja, a partir de uma perspectiva prática, não deveria nos surpreender. Elas baseiam-se na ideia de que a técnica é algo vinculado ao ser humano. Em outras palavras: a técnica é compreendida comumente como uma produção humana, como um fazer do homem. A pergunta que nos interessa aqui é a seguinte: Até que ponto o domínio de uma compreensão antropológica da técnica dificulta ou até mesmo impede que vejamos outras diversas possibilidades de pensar a técnica?

Ernst Kapp e Arnold Gehlen são dois exemplos marcantes da antropologização do fenômeno da técnica que merecem ser rapidamente mencionados aqui. Eles não estão interessados somente em problemas envolvendo as consequências da técnica e o modo como administrá-los, mas questionam o que é a técnica. Todavia, ambos apresentam concepções em que o homem representa um papel fundamental. Para Kapp, que escreveu a primeira filosofia da técnica - ao menos a primeira que explicitamente evoca esse título -, em 1877 (Princípios de uma filosofia da técnica) ${ }^{1}$, a técnica deve ser entendida como uma "projeção orgânica". Ou seja, os artefatos e sistemas técnicos devem ser entendidos como uma projeção dos órgãos humanos: um martelo poderia ser entendido a partir do punho, os óculos ou um microscópio, como uma projeção dos olhos humanos, um sistema telegráfico como uma projeção do sistema nervoso, e assim por diante. Desse modo, conclui Kapp, no mundo da técnica o homem poderia reconhecer toda sua dimensão e grandeza (Luckner, 2008, p. 24). Arnold

${ }^{1}$ Grundlinien einer Philosophie der Technik. Zur Entstehungsgeschichte der Kultur aus neuen Gesichtspunkten. Braunschweig: Verlag George Westermann, 1877.

Filosofia e Educação - ISSN 1984-9605

Volume 6, Número 3 - Outubro de 2014 
Gehlen, por sua vez, desenvolve, em sua antropologia ${ }^{2}$, uma teoria da "compensação" (Organersatz). A essência da técnica deve aqui também ser buscada no homem, mais precisamente, em suas deficiências e carências de ordem física e instintiva. O homem é incapaz de se adaptar satisfatoriamente ao seu meio-ambiente. Sua estrutura corporal, por exemplo, não permite que consiga atingir velocidades elevadas, caso tenha que fugir de algo que lhe ofereça perigo. Mesmo os seus instintos não atingem a eficiência de diversos outros animais. A técnica está ligada a essa deficiência, surge justamente para compensar a incompletude natural do ser humano.

Heidegger também quer pensar a técnica, mas procura um outro caminho. A princípio, deseja distanciar-se de concepções antropológicas da técnica e coloca a "questão da técnica" em outra dimensão. Sem dúvidas, Kapp e Gehlen tentaram pensar, cada qual de seu modo, a essência da técnica. Todavia, não é fácil colocar Heidegger nessa mesma esteira. Heidegger também pergunta pela essência da técnica, mas o faz de um modo distinto. A própria palavra essência adquire aqui um significado peculiar. "Essência" não pode ser confundida com o termo latino "essentia", nem com as ideias de substância, substrato, algo estático, permanente, atemporal, que determina o ente e que pode ser perscrutado por um olhar contemplativo. "Essência" (Wesen) é verbo. Isso quer dizer: é mudança, é movimento, tem a ver com o que vigora, com acontecimento. De certo modo, Kapp e Gehlen partem desde o início de uma pré-concepção daquilo que é técnico e creem que a origem da técnica - seja ela uma projeção orgânica, seja ela uma forma de compensar deficiências e carências biológicas - encontra-se no ser humano. Com Heidegger, entretanto, poderíamos dizer que tanto Kapp como Gehlen não colocam a "questão da

${ }^{2}$ Desenvolvida em diversos trabalhos como, por exemplo, em O homem. Sua natureza e sua posição no mundo (Der Mensch. Seine Natur und seine Stellung in der Welt (Berlin: Junker und Dünnhaupt, 1940) e A alma na era da técnica (Die Seele im technischen Zeitalter. Sozialpsychologische Probleme in den industriellen Gesellschaft. Hamburg: Rowohlt, 1957).

Filosofia e Educação - ISSN 1984-9605

Volume 6, Número 3 - Outubro de 2014 
técnica" - mais ainda, nem sequer percebem a essência da técnica é algo distinto da técnica, ou seja, "não é de modo algum algo técnico" (Heidegger, 1997, p. 43).

"A questão da técnica" (Heidegger, 1997), conferência proferida em 1953 e publicada em 1954, tem como ponto de partida aquilo que Heidegger chama de "determinação instrumental e antropológica da técnica". Essa determinação pode ser resumida em duas afirmações: "a técnica é um meio para fins" e a "técnica é um fazer do homem". Heidegger observa com perspicácia como essas duas concepções estão interligadas. De um lado, os produtos técnicos apresentam-se a nós constantemente como meros meios para atingir fins. Uma chave de roda, para trocar o pneu, para que o carro rode, para que me leve a algum lugar, para que pratique uma atividade, e assim por diante.

É nesse contexto, todavia, que não somente utilizamos e consumimos, mas pensamos e fazemos os diversos artefatos como, por exemplo, ferramentas, eletrodomésticos, máquinas, os aparelhos eletrônicos e de informática. Estamos aqui inseridos em uma "lógica" que, todavia, não diz respeito somente à construção e uso de aparelhos e máquinas, mas se estende também à organização do trabalho e de outras atividades humanas. Criamos programas, formulários, sistemas, procedimentos que atuam como meios para atinjamos determinados objetivos - objetivos que são colocados pelo próprio homem ora com o intuito de facilitar o seu labor, ora para satisfazer à necessidade de criar algo que conceda maior estabilidade e segurança a sua vida. Dessa concepção instrumental e antropológica da técnica brota a convicção de que o homem pode, de alguma forma, exercer domínio sobre a técnica. Por mais complexa que seja, por mais difícil que seja prever suas consequências e seu campo de atuação, a técnica é em si neutra e está à disposição do homem. Cabe a ele querer, planejar, controlar, dirigir, por fim, impedir e cuidar para que a técnica não ultrapasse certos limites. Heidegger até admite que essa não é uma interpretação incorreta:

Filosofia e Educação - ISSN 1984-9605

Volume 6, Número 3 - Outubro de 2014 
É correto dizer: também a técnica moderna é um meio para fins. Por isso, todo esforço para conduzir o homem a uma correta relação com a técnica é determinado pela concepção instrumental da técnica. Tudo se reduz ao lidar de modo adequado com a técnica enquanto meio. Pretende-se, como se diz 'ter espiritualmente a técnica nas mãos'. Pretende-se dominá-la. O querer-dominar se torna tão mais iminente quanto mais a técnica ameaça escapar do domínio dos homens. (Heidegger, 1997, p. 45)

Contudo, é a partir dessa "correta" interpretação da técnica, criticando-a, que Heidegger busca revelar a "verdade" da "essência da técnica", pois: "o que é meramente correto ainda não é o verdadeiro" (Heidegger, 1997, p. 45).

Já aqui, no início de sua conferência, percebemos claramente o que está em jogo: a verdade. Para Heidegger, a técnica não pode ser entendida, na sua essência, a partir da lógica "meios-fins" - muito menos, como uma produção humana. Trata-se antes de "um modo de desabrigar" (Heidegger, 1997, p. 53), ou seja, de um "modo de verdade", não entendida como correspondência ou adequação, mas como um "processo", como um acontecimento - um acontecimento em uma dimensão ontológica em que o ser mesmo é "descoberto", é "desabrigado", e que não deve ser entendido de maneira alguma como produto de uma atividade do homem. Embora participe dele, o homem "não dispõe do descobrimento por onde a realidade a cada vez se mostra ou recai" (Heidegger, 1997, p. 63). Assim, a técnica "é algo que o homem por si mesmo não domina" (Heidegger, 2009, p. 27). Pelo contrário, é ela que, de certo modo, "domina" o homem, e que determina o modo como as coisas nos são dadas.

É por isso que Heidegger insiste em afirmar: a essência da técnica não é de modo algum algo técnico. A ideia da técnica como instrumento, como um meio para um fim, encobre justamente esse fato - impede,

Filosofia e Educação - ISSN 1984-9605

Volume 6, Número 3 - Outubro de 2014 
portanto, nosso acesso à sua essência. Mais do que isso: ela nos faz completamente esquecer aquele acontecimento prévio que está por trás de toda e qualquer lida com as coisas, com os outros e com nós mesmos.

É claro, precisamos nos lembrar, de que Heidegger, na época de suas reflexões sobre a técnica, já havia se voltado ele mesmo para uma "história do ser", para o fato que o ser se manifesta de modos distintos em distintas épocas. A técnica moderna também é um "desvelar", um "desabrigar" que faz com que os entes, ou seja, tudo o que é, se manifesta de um determinado modo. Não há como o homem se esquivar desse fato. Ele mesmo é um ente, e como tal está por assim dizer à mercê do modo de "desvelamento" do ser. É por isso que Heidegger, em outro momento, não hesita em afirmar: "só temos relações puramente técnicas" (Heidegger, 2009, p. 28).

Não restam dúvidas que estamos diante de um impasse. Como podemos afinal apreender a essência da técnica enquanto essência da verdade, se partirmos da premissa que todas as nossas atividades, todas nossas relações com as coisas, inclusive o pensar, já estão pré-determinadas pela técnica?

Não é por acaso que Heidegger, desde o início de seu texto, problematiza o modo como podemos nos aproximar da "questão da técnica". Trata-se de algo que não pode ser fixado e apreendido, definido como isso ou aquilo, nem sequer pensado, se entendermos por pensar um refletir sobre alguma coisa. A "essência da técnica" é antes algo, melhor dizendo, um "acontecimento", a que somente podemos "responder" ou "corresponder" caso nossa existência esteja apta, ou seja, aberta a isso. Logo no início de seu discurso, Heidegger aponta para a atitude de abertura necessária para captarmos a essência da técnica:

A seguir, questionaremos a técnica. O questionar constrói num caminho. Por isso é aconselhável, sobretudo, atentar para o caminho e não permanecer preso a proposições e títulos particulares. $\mathrm{O}$ caminho é um caminho do pensamento. Todos os caminhos do pensamento,

Filosofia e Educação - ISSN 1984-9605

Volume 6, Número 3 - Outubro de 2014 
mais ou menos perceptíveis, passam de modo incomum pela linguagem. Questionamos a técnica e pretendemos com isso preparar uma livre relação para com ela. A relação é livre se abrir nossa existência $<$ Dasein $>$ à essência da técnica. Caso correspondamos à essência, estaremos aptos a experimentar o técnico $<$ das Technische $>$ em sua delimitação" (Heidegger, 1997, p. 41).

Em outras palavras: o caminho não é fácil - é um caminho de pedras, ou melhor, "um caminho do pensar". Exige, portanto, uma atitude diferenciada. Não se trata de analisar, entender, compreender as diversas manifestações da própria técnica, mas sim de corresponder à sua essência. Só assim - "caso correspondamos à essência" - estaremos aptos a "experimentar o técnico".

Mas o que significa aqui "corresponder"? Seja o que for, é certamente algo muito distinto daquilo que normalmente denominamos conhecimento técnico - até mesmo porque todo conhecimento técnico não se preocupa com a essência da técnica. O conhecimento técnico, independentemente de sua intensidade e profundidade, já é totalmente dominado e determinado pela essência da técnica. Corresponder à essência requer uma atitude, melhor dizendo, uma mudança de atitude. Entre as tantas passagens que evocam essa atitude, esse "outro pensar", uma se mostra muito apropriada, para o que estamos querendo refletir. Heidegger sugere: "Basta perceber (...) o apelo que já sempre reivindica o homem, de maneira tão decisiva, que, somente neste apelo, ele pode vir a ser homem". (Heidegger, 2012, p. 22)

"Basta perceber o apelo" - é justamente aí aonde Heidegger quer chegar com seu discurso. Suas palavras possuem um caráter quase que evocativo. Ele não está interessado somente em criticar as concepções antropológicas e apontar para uma dimensão ontológica da técnica. Seu texto é mais pretensioso. Heidegger quer fazer com que percebamos o apelo, ou seja, tenta nos tornar sensíveis para o fato de que em tudo isso que 
chamamos técnica está o movimento do próprio ser se revelando - e, portanto, de algo que determina a própria humanidade do homem, seu "vir a ser homem".

Aqui reside um ponto fundamental na "questão da técnica" colocada por Heidegger. O "técnico" é visto como um "acontecimento" que transcende o homem e sua capacidade de pensar e agir. Enquanto "armação", "composição" (Gestell), enquanto um "modo de descobrimento", a essência da técnica não é uma questão humana, mas um modo de manifestação do próprio ser que constitui e determina não somente a construção de novos aparelhos, equipamentos, máquinas, mas sim todo o envolvimento do homem com o mundo e consigo mesmo - toda "relação do homem com aquilo que é" (Heidegger, 1988, p. 18). Assim, uma "verdadeira" filosofia da técnica não tem alternativa que não seja a de se mover nesse plano ontológico. Qualquer esforço de refletir e ponderar sobre a relação do homem com os artefatos produzidos por aquilo que denominamos técnica moderna, ou sobre as consequências do desenvolvimento dessa técnica, ou mesmo sobre o poder determinante da técnica em nossos modos de vida, já estaria fadada ao fracasso. O que resta ao homem não é um esforço determinado pelo querer e pela vontade, mas antes uma atitude de espera, de "escuta", de "serenidade" (Gelassenheit), de "correspondência" à essência da técnica.

Há um ponto que merece ser mencionado nesse contexto - e que mereceria uma análise mais meticulosa. Não pretendemos, às pressas, acusar o pensamento de Heidegger de antropocêntrico, afinal ele mesmo e a maioria de seus intérpretes insistem, com certa razão, em afastar-se radicalmente de uma centralização excessiva no homem, bem como de concepções antropológicas da técnica. Todavia, não se pode fechar os olhos para o fato de que a "questão da técnica" afeta diretamente o ser humano. Poder-se-ia até perguntar: Não seria o "pensar" a essência e verdade da 
técnica, no fundo, um pensar sobre, melhor dizendo, um "novo pensar"3 do homem e de seu modo de ser? Diversas passagens parecem confirmar essa desconfiança. Já a preocupação de Heidegger com a necessidade de “corresponder à essência da técnica", mostra um papel especial reservado ao ser humano. Afinal, é ele que terá - e Heidegger parece acreditar que ele seja capaz disso - de corresponder.

Em outras passagens, o homem aparece no centro das reflexões de Heidegger. Isso ocorre principalmente quando o problema da "ameaça" e do "perigo" diante da técnica, compreendida como "armação", é tematizado.

O homem está tão decididamente preso à comitiva do desafiar da armação, que não a assume como uma responsabilidade, não mais dá conta de ser ele mesmo alguém solicitado e, assim também, não atende de modo algum ao fato de que, a partir de sua essência, ele eksiste no âmbito de um apelo e que, por isso, nunca pode ir somente ao encontro de si mesmo. (Heidegger, 1997, p, 79)

Finalmente, não podemos deixar de destacar que as preciosas reflexões de Heidegger sobre a técnica também partem de uma determinada pré-compreensão - a técnica é, em sua essência, verdade no sentido de descobrimento. Isso nos coloca, entretanto, diante de um problema: até que ponto essa pré-compreensão nos limita ao pensarmos uma filosofia da técnica? Não colocaria esse pensamento "originário" um obstáculo, ou até mesmo uma barreira intransponível para compreendermos "outros" pensamentos sobre a técnica?

Alfred Nordmann, que também discute Heidegger em sua introdução à filosofia da técnica (Nordmann, 2008), parece ter captado bem as dificuldades que teremos se nos ativermos demais a uma determinação da técnica.Por isso, tenta abandonar a ideia de primeiramente fixar um conceito

3 Esse "outro", esse "novo pensar" é tema central do livro de Oswaldo Giacoia Jr.: Heidegger urgente. Introdução a um novo pensar. São Paulo: Três Estrelas, 2013.

Filosofia e Educação - ISSN 1984-9605

Volume 6, Número 3-Outubro de 2014 
ou uma concepção de técnica a partir do qual, então, pudéssemos refletir sobre ela. Desse modo, não estaríamos preocupados, por exemplo, somente com aquilo que é, segundo Heidegger, "verdadeiro", mas também com tudo aquilo que é "correto" - uma filosofia da técnica verdadeira e correta. Para isso, Nordmann apresenta uma interessante ideia - inspirada no pensamento de Grunwald e Julliard - em que a técnica é primeiramente concebida como um "conceito de reflexão" (Reflexionsbegriff), ou seja, um conceito que não se refere a um objeto específico, mas que se baseia na comparação de representações e imagens, estando assim sujeito a transformações históricas. Nordmann acredita poder, desse modo, não somente deixar para trás os problemas com definições, mas, principalmente, fazer jus a "uma compreensão indefinida" da técnica. O desafio seria desenvolver uma filosofia da técnica para a qual a técnica, a princípio, não é nada senão aquilo "que pensamos que é quando falamos em geral de técnica". Enfim, trata-se de uma concepção em melhores condições de nos ajudar a pensar sobre o significado da técnica para nós e, finalmente, sobre a nossa posição como seres humanos diante de um "mundo tecnicizado".

Se técnica é aquilo que pensamos que é quando de maneira geral falamos da técnica, então filosofia da técnica se interessa primeiramente por esses movimentos de reflexão, bem como pelo modo como eles nos conduzem, a partir de uma pré-compreensão irrefletida, a questões sobre como a nossa relação com o mundo é organizada, passando pela técnica, quer dizer, a questões da antropologia filosófica, da filosofia da história, da filosofia da natureza, da filosofia do conhecimento e da ciência“. (Nordmann, 2008, p. 13 , tradução nossa). ${ }^{4}$

\footnotetext{
${ }^{4}$ No original: "Wenn Technik das ist, was wir meinen, wenn wir allgemein über die Technik reden, dann interessiert sich Technikphilosophie zunächst einmal für diese Reflexionsbewegungen und dafür, wie sie uns von einem unreflektierten Vorverständnis zu Fragen darüber führen, auf welche Weise unser Verhältnis zur Welt über die Technik organisiert ist, d.h. zu den Fragen der philosophischen Anthropologie, Geschichtsphilosophie, Naturphilosophie, Erkenntnis- und Wissenschaftsphilosophie"
} 
Técnica genética, técnica agrária, técnica culinária, técnica digital, técnicas de magia, de ensino, de informação, eletrotécnica, técnica musical etc. - seriam todas elas técnica no mesmo sentido? ${ }^{5}$ Se quisermos pensar uma filosofia da técnica não podemos deixar simplesmente de lado as particularidades dessas distintas modalidades. Se a técnica hoje de algum modo realmente influi em todos os âmbitos da vida humana, não há como uma filosofia da técnica abstrair-se de toda complexidade de nossas vivências, por mais triviais e banais que possam ser. Pensar a técnica filosoficamente exige uma atitude de abertura ao constante diálogo com outras disciplinas, com outros âmbitos do conhecimento, com os protagonistas das mais diversas atividades.

Além disso, uma filosofia da técnica precisaria considerar os diversos aspectos culturais que determinam a relação com a técnica. Esse aspecto é frequentemente deixado de lado, como se a técnica fosse algo homogêneo. Como os seres humanos vivenciam a técnica em uma determinada cultura? Poder-se-ia aqui descobrir diferenças marcantes, condicionadas culturalmente? Até que ponto podemos falar da técnica como um fenômeno transcultural? Ou seria a técnica um fenômeno estritamente ocidental - de origem grega (techne) - e que contagiou, aos poucos, outras culturas? Seria este "contágio" antes um processo desencadeado fundamentalmente pela ideia moderna de técnica? Desse modo, poderíamos constatar recepções distintas da técnica moderno-ocidental por diferentes culturas, por diferentes "mundos circundantes" (Umwelten), estaríamos mais

\footnotetext{
${ }^{5}$ Não poderíamos, talvez, incluir aqui a ideia de "técnica filosófica" e compreender a própria praxis filosófica como uma expressão da técnica? Não seria justamente a "fabricação", como sugere discretamente Hannah Arendt, uma das características fundamentais do filosofar e, de maneira geral, de toda atividade acadêmica - fabricação de textos, de ideias, de argumentos, de pensamentos, de conceitos? Afinal, a ação, o discurso, e também o pensamento "[p]ara que se tornem coisas mundanas, isto é, feitos, fatos, eventos e modelos de pensamento e ideias, devem primeiro ser vistos, ouvidos e lembrados, e então transformados em coisas, reificados, por assim dizer" (ARENDT, 2010, p. 117). Se pensarmos na prática filosófica: não seria o homo philosophicus essencialmente um homo faber?
}

Filosofia e Educação - ISSN 1984-9605

Volume 6, Número 3-Outubro de 2014 
abertos para a diversidade de interpretações da técnica, estaríamos dispostos a discutir concepções não somente verdadeiras, mas corretas da técnica.

\section{Bibliografia}

ARENDT, Hannah. A condição bumana. Tradução de Roberto Raposo. Revisão e apresentação técnica de Adriano Correia. Rio de Janeiro: Forense Universitária, 2010.

HEIDEGGER, Martin. A questão da técnica. Die Frage nach der Technik. Tradução e apresentação de Marco Aurélio Werle. In: Cadernos de Tradução, n. 2, Departamento de Filosofia da USP, 1997.

HEIDEGGER, Martin. Ensaios e Conferências. Trad. de Emmanuel Carneiro Leão, Gilvan Vogel e Marcia Sá Cavalcante Schuback. Petrópolis: Vozes; Bragança Paulista: Ed. Universitária São Francisco, 2012.

HEIDEGGER, Martin. Gelassenheit (1944-1955). Pfullingen: Günther Neske Verlag, 1988.

HEIDEGGER. Martin. "Já só um Deus nos pode ainda salvar!". Tradução e notas de Irene Borges Duarte. Covilhã: LusoSofia:press, 2009.

LUCKNER, Andreas. Heidegger und das Denken der Technik. Bielefeld: Transcript Verlag, 2008

NORDMANN, Alfred. Technikphilosophie zur Einführung. Hamburg: Junius, 2008. 